\title{
A propaganda de alimentos: orientação, ou apenas estímulo ao consumo?
}

\author{
Food advertising: advice or merely stimulation of consumption?
}

Bianca Ramos Marins ${ }^{1}$ Inesita Soares de Araújo ${ }^{2}$ Silvana do Couto Jacob ${ }^{3}$
${ }^{1}$ Escola Politécnica de Saúde Joaquim Venâncio, Fundação Oswaldo Cruz. Avenida Brasil 4365, Manguinhos. 21041-900 Rio de Janeiro RJ. biancamarins@fiocruz.br ${ }^{2}$ Instituto de Comunicação e Informação Científica e Tecnológica em Saúde, Fundação Oswaldo Cruz. ${ }^{3}$ Instituto Nacional de Controle de Qualidade em Saúde, Fundação Oswaldo Cruz.

\begin{abstract}
Current advertising messages for food products deserve special attention, since they indicate that the media has played a central role in shaping new eating habits. The food industry, seeking to serve a new customer segment (increasingly preoccupied with health and physical well-being), and with a specific interest in this promising market, has intensified its marketing strategies for stimulating consumption of diet and light food products. This study analyzed 20 food advertisements published from June to October 2006 in Brazilian magazines and newspapers with nationwide circulation. The following elements were analyzed in the advertisements: the advertiser; the audience; the language; and the message. It was seen that the advertising message mainly targeted women, proposing guilt-free consumption, promising a combination of esthetics and health. In order to enhance their product, several advertisements omitted relevant nutritional information while others promoted hazardous combinations with pharmaceutical products, and still others induced the target public to replace regular meals with their product. The results signal the need to broaden the discussion on the strategies for food advertising, as the citizen's right to information and health cannot be subjugated to market values.

Key words Food advertising, Information, Communication, Health surveillance
\end{abstract}

Resumo As mensagens sobre alimentação veiculadas nos meios de comunicação merecem atenção, pois estudos apontam que a mídia exerce papel fundamental na formação de novos hábitos alimentares. Visando atender a um novo perfil de consumidores preocupados com a saúde e o bemestar físico e interessada nesse mercado promissor, a indústria intensifica as estratégias de estímulo ao consumo de determinadas categorias de alimentos, como os produtos diet e light. Este estudo analisou 20 peças publicitárias de alimentos veiculadas em revistas e jornais de circulação nacional entre junho e outubro de 2006, contemplando: o emissor; o destinatário; a linguagem e a mensagem. Constatou-se que o discurso publicitário focou principalmente as mulheres, propondo o consumo sem culpa e prometendo a combinação entre estética e saúde. Na busca da valorização do produto, as peças publicitárias secundarizaram informações nutricionais relevantes, outras realizaram combinações perigosas para a saúde, como a associação do alimento a medicamentos e a indução a substituição de refeições pelo produto em questão. Os resultados sinalizam a necessidade de se ampliar a discussão sobre as estratégias da publicidade de alimentos, pois o direito do cidadão à informação e à saúde não podem estar subjugados a valores de mercado.

Palavras-chave Propaganda de alimentos, Informação, Comunicação, Vigilância sanitária 


\section{Introdução}

Um novo perfil de consumidores, preocupados com a estreita relação alimentação-saúde-doença, vem exigindo das indústrias alimentícias novas estratégias de mercado. Desde a década de 90, estas indústrias vêm intensificando, através da publicidade, o estímulo ao consumo de novos produtos, entre eles os Alimentos para Fins Especiais. Estes estão adequados à utilização em dietas, diferenciadas ou opcionais, que atendem as necessidades de pessoas em condições metabólicas e fisiológicas especiais, nos quais são introduzidas modificações no conteúdo de nutrientes. Neste sentido, também existe a preocupação em relação aos produtos contendo informação nutricional complementar, com o atributo light, conforme descrito em legislação específica.

A vida moderna, associada ao desenvolvimento de novas tecnologias aplicadas à área de alimentos, impulsionou o aumento do consumo de produtos industrializados. Por outro lado, as indústrias de alimentos investem cada vez mais recursos em propaganda de seus produtos, com o objetivo de conquistar novos e fieis consumidores. Neste contexto, com um mercado em expansão, surge também um novo perfil de consumo, o novo consumidor deseja alimentos equilibrados do ponto de vista nutricional, de fácil preparo e sensorialmente atraentes.

As mensagens sobre alimentação veiculadas pelos meios de comunicação merecem especial atenção, entre outros fatores pelos estudos que apontam que a mídia tem exercido papel fundamental na formação de novos hábitos alimentares. Quando se trata de alimentos infantis, já em 1974, Muller, citado por Araújo et al. ${ }^{1}$, apontou a propaganda como forma de influenciar a utilização de fórmulas infantis e leite integral utilizado em fórmulas caseiras, alimentos complementares e cereais, veiculados habitualmente por mamadeiras como forma substituta ao aleitamento. Outro estudo que evidencia a influência da propaganda sobre o público infantil relatou que crianças que passam muitas horas expostas à televisão são mais vulneráveis ao anúncio de alimentos de alto valor calórico, além do fato de não estarem praticando atividades físicas, situação esta que predispõe para o aumento do risco para obesidade e sobrepeso ${ }^{2}$.

Outro grupo sujeito às estratégias mercadológicas é o de jovens, frequentemente bombardeados por informações que os levam a crer em fórmulas de resultado imediato capazes de tornálos mais atraentes, desde que se tornem adeptos do modismo e, consequentemente, aceitos por seus pares. Nesse grupo, a busca incessante por moldes estéticos corporais tem contribuído de forma significativa para o aumento de doenças como a bulimia e a anorexia, principalmente entre o público feminino. Para Santi ${ }^{3}$, atualmente, a imagem do corpo está submetida a moral do espetáculo. O sucesso depende de certos atributos corporais. Entre os principais, estão a imagem e os valores difundidos pelas celebridades, o culto à magreza e o culto a um corpo sarado, de acordo com o linguajar dos jovens.

Para Lyra ${ }^{4}$, a mídia, através da publicidade, é uma poderosa ferramenta para determinar o comportamento dos indivíduos quanto ao consumo, pois ela induz as necessidades. Considerando a realidade econômica e cultural, a autora aponta que o sucesso dos anúncios publicitários está atrelado ao nível de correspondência com o grupo social.

Para explicar o método de persuasão e consequentemente a conquista do público, Aldrighi definiu o modelo ideal para obter sucesso nas peças publicitárias como sendo um processo encadeado, com as seguintes etapas: intervir/ativar as expectativas do consumidor (crenças, desejos, saberes...); produzir mensagens que alimentem estas expectativas; induzir a compra; consumo/ uso do produto; avaliar as expectativas; expectativas-positivas (satisfação) representam predisposição para a recepção de novas mensagens e a recepção de novas mensagens favorece a fidelidade à marca ${ }^{5}$.

Burrowes ${ }^{5}$ enuncia que mensagens utilizadas pelas peças publicitárias buscam identidade sob o ponto de vista linguístico, como também sobre o conhecimento de valores junto ao consumidor. Ao se adquirir um produto se adquire também os valores simbólicos atribuídos ao mes$\mathrm{mo}^{6}$. A publicidade induz e/ou ratifica tendências, estimula o consumo, a forma de consumo, quem pode ou o que deve consumir (desde que se pague pelo produto) e ainda identifica o produto como fator de classificação em um determinado grupo social.

Nascimento ${ }^{7}$ descreve sobre estas tendências, no caso do consumo de medicamentos

Diretamente junto à população consumidora de produtos farmacêuticos, a propaganda é utilizada como mais um instrumento de reforço da, já existente, cultura da medicalização. Este fator atua fortemente associado à ideologia de consumo - disseminada na sociedade - como caminho mais rápido de se alcançar saúde, bem-estar e, em última instância, a felicidade. 
Quando pensamos sobre a publicidade de produtos relacionados à saúde, como medicamentos, alimentos e cosméticos, podemos inferir uma relação direta entre esses elementos que necessita ser analisada à luz de parâmetros éticos que levem em conta o direito à informação e à saúde, permitindo uma maior e melhor aproximação de ações que possibilitem minimizar os riscos advindos do consumo induzido de forma indiscriminada. Neste sentido, adquire relevância a pesquisa e a discussão sobre a propaganda destes produtos, para adoção de medidas cautelares por parte de órgãos gestores como a Agência Nacional de Vigilância Sanitária (ANVISA).

Nascimento ${ }^{7}$ destaca que a principal causa de intoxicação humana no país advém de produtos farmacêuticos e não foi por acaso que a ANVISA vem desenvolvendo, com a cooperação de centros universitários, um trabalho de fiscalização e monitoração de peças publicitárias sobre medicamentos, com o intuito de evitar o uso inadequado destes produtos (a ideia é que gradualmente a fiscalização e a monitoração das peças publicitárias sejam estendidas às demais categorias de produtos sujeitos à Vigilância Sanitária).

O Decreto-Lei n ${ }^{\circ} 986$ de $1969^{8}$, que institui as Normas Básicas sobre alimentos, torna proibida a divulgação de textos e matérias de propagandas, qualquer que seja o veículo utilizado, para informações contrárias àquelas que foram aprovadas para constar no rótulo. A rotulagem deve ser clara, objetiva e fidedigna conforme as diretrizes descritas no Regulamento Técnico para a Rotulagem de Alimentos. Desta forma, assim como os rótulos, a propaganda de alimentos não pode induzir o consumidor a erro, equívoco ou engano. Informações adequadas e compreendidas pelo consumidor permitirão que o ato de consumir gere uma atitude prévia de reflexão sobre a necessidade do consumo daquele bem.

Os alimentos para fins especiais, conceituados como especialmente formulados ou processados, nos quais se introduzem modificações no conteúdo de nutrientes, adequados a utilização em dietas, diferenciadas elou opcionais, atendendo as necessidades de pessoas em condições metabólicas e fisiológicas específicas, (Portaria SVS/MS no 29, de 13 de janeiro de 1998$)^{9}$ são classificados em: alimentos para dietas com restrição de nutrientes; alimentos para ingestão controlada de nutrientes e alimentos para grupos populacionais específicos9. De acordo com o Manual de Monitoramento de Propaganda de Produtos sujeitos a Vigilância Sanitária (Anvisa) ${ }^{10}$, a propaganda destes alimentos deve observar as determinações gerais para alimentos, previstas no Decreto-Lei $\mathrm{n}^{\circ} 986$ de $1969^{8}$ e as dispostas no respectivo Regulamento Técnico para a categoria do produto.

Na Lei $n^{\circ} 11.265$ de 03 de janeiro de $2006^{11}$, que regulamenta a comercialização de alimentos para crianças na primeira infância e também a de produtos de puericultura correlatos, objetiva-se a regulamentação da publicidade e do uso apropriado dos alimentos. A Lei também regulamenta o uso de mamadeiras, bicos e chupetas, visando a proteção e incentivo do aleitamento exclusivo nos primeiros seis meses de idade, assim como a continuidade do aleitamento até os dois anos de idade, após a introdução de novos alimentos na dieta dos lactentes e das crianças de primeira infância.

Outra necessidade apontada é a regulamentação sobre a oferta, propaganda, publicidade, informação e outras práticas correlatas cujo objeto seja a divulgação ou promoção de alimentos com quantidades elevadas de açúcar, de gordura saturada, de gordura trans, de sódio e de bebidas com baixo teor nutricional. De acordo com Henriques et al. ${ }^{12}$, a informação clara e adequada sobre os riscos do consumo exagerado de determinados produtos alimentícios pode contribuir para hábitos alimentares mais saudáveis.

Sob outra ótica, as ciências da saúde tomam emprestado o objeto de estudo das ciências sociais para compreender como as estratégias da publicidade vêm influenciando novos hábitos. O objetivo do presente estudo foi analisar as estratégias mercadológicas de estímulo ao consumo, observadas em peças publicitárias de alimentos veiculadas em revistas e jornais de circulação nacional.

\section{Procedimento metodológico e corpus de análise}

Neste estudo, foram analisadas 20 peças publicitárias encontradas em nove revistas femininas de atualidades ou de "vida-saudável", disponíveis nas salas de espera de consultórios e salões de beleza, e em encartes semanais de dois jornais diários. A coleta das peças ocorreu no período de junho a outubro de 2006. Os produtos alimentícios anunciados foram: sobremesas lácteas cremosas; barras de cereais; bala; pão de forma; bebidas lácteas (leites e iogurtes); cereais; adoçante à base de sucralose; bebida à base de soja; alimentos infantis; embutidos e pizza. O método de análise foi qualitativo e foram contemplados em cada peça os seguintes elementos: o emissor (quem fala); o destinatário (para quem fala); a linguagem (como fala) e a mensagem (o que fala). 


\section{Descobertas}

O resultado da análise das vinte peças publicitárias possibilitou observar:

Principais marcas do emissor: presença de telefone (0800) e site para contato; alertas sobre a necessidade de bons hábitos de vida e dieta equilibrada (constroem a imagem do emissor responsável, que cuida da saúde do leitor); destaque para a marca dos produtos e sites da indústria alimentícia; patrocínio de atividades esportivas (imagem de responsabilidade social).

Principais marcas do destinatário: a maioria das peças estava dirigida ao público feminino; todas falam a uma leitora interessada na boa forma com saúde.

Principais marcas da linguagem: forte recurso à adjetivação, a intertextos culturais e a metáforas; uso de termos em outro idioma, como marca de sofisticação; expressões de efeito sem base técnica-científica.

Principais marcas das mensagens (atributos do produto, argumentos): imagens expressam felicidade, vitalidade, disposição, saúde física e mental; as características atribuídas ao produto: superioridade, credibilidade, confiança, alta qualidade, inovação e beneficio à saúde; personalidades da mídia conferindo legitimidade ao produto; o prazer, a satisfação e a saúde como álibis contra a culpa do consumo; convites para experimentar os outros produtos da linha ou marca; algumas peças induzem a substituição de refeições; atributos diet e light receberam destaque e por vezes são empregados de forma inadequada; informações nutricionais e advertências em relação ao uso do produto são inexistentes ou apresentadas sem destaque, em relação ao conjunto da peça.

\section{Algumas reflexões sobre a comunicação}

De acordo com Strozenberg ${ }^{13}$, a mensagem da propaganda também constitui um espaço de interlocução, onde interagem ativamente múltiplos interlocutores, tanto no pólo da emissão quanto no da recepção, sendo a elaboração das estratégias publicitárias marcada pela negociação de interesses.

A noção de comunicação como espaço de negociação também está presente em Araújo ${ }^{14}$, que concebe a comunicação como um mercado simbólico. Neste, os sentidos sociais estão em permanente negociação: são produzidos, circulam e são apropriados (consumidos). A prática comunicativa pode então ser considerada como o ato de ativar o circuito produtivo dos sentidos sociais. Esse mercado é operado por comunidades discursivas que, segundo esse autor,

[...] negociam sua mercadoria - seu próprio modo de perceber, classificar e intervir sobre o mundo e a sociedade - em busca do poder simbólico, o poder de constituir a realidade.

Por este enfoque, o receptor/consumidor também é sempre um produtor de novos sentidos. Tal concepção, no âmbito da saúde pública, representa uma ruptura com o modelo dominante de comunicação, de natureza transferencial, bipolar e unidirecional, que acredita na modelagem de atitudes, no qual os sujeitos envolvidos estão alocados em pólos demarcados - emissor e receptor, com realidades distintas e distantes - onde um tudo sabe e o outro tudo precisa aprender. A ruptura implica em pensar a comunicação em saúde como um processo amplo, complexo, dinâmico, polifônico, operando em espaços dialógicos caracterizados por divergências e pelo confronto e negociação de interesses.

Uma prática advinda dessa concepção favoreceria a intervenção ativa dos sujeitos em suas realidades, tornando-os mais capazes de interagir com os riscos e condições de saúde. O primeiro passo para garantir esta possibilidade é a circulação de informações que não só possam ser apropriadas pelos interlocutores, mas que também contribuíssem para ampliar sua capacidade de tomar decisões. Fortes ${ }^{15}$ argumenta que a informação tem caráter essencial quando se busca a participação da sociedade e o controle social sobre as políticas públicas de saúde, suas prioridades e formas de implementação. Assim, o direito à informação é inalienável do direito à saúde e condição de efetividade deste.

E em relação à propaganda de alimentos? Que estratégias de informação e comunicação são utilizadas? Será que são capazes de provocar reflexões e passíveis de apropriação pelo cidadão, que se defronta constantemente com um sistema produtivo que o classifica como consumidor? Quais os reais riscos e danos à saúde frente a tantos apelos?

\section{O que diz a vigilância sanitária?}

Talvez estas perguntas nos provoquem angústia e/ou aflição diante de um sistema voraz que persiste em dizer o que, como, quando e onde consumir. Uma forma possível de refletir sobre elas é a partir dos parâmetros da Vigilância Sanitária.

Quando há riscos à saúde pública, é atribuição da Vigilância Sanitária intervir nas relações de consumo. Cabe à Vigilância Sanitária: 
lita que as ações em vigilância tenham um caráter mais completo, inserindo-as na esfera da produção e do consumo, na qual se originam grande parte dos problemas de saúde que demandam intervenção.

Desta forma, a Vigilância Sanitária deve compreender como se estabelece o processo do consumo como forma de melhor intervir, pois a divulgação de informações incorretas, equivocadas ou incompletas pode acarretar danos à saúde. Para isso, Fortes ${ }^{15}$ aponta a necessidade de instrumentos que protejam a saúde coletiva, pois a relação da vigilância sanitária com a sociedade deve estar pautada na noção de cidadania, de sujeitos de direitos e não apenas na de consumidores.

De acordo com o Manual de Monitoramento de Propaganda de Produtos sujeitos a Vigilância Sanitária (Anvisa) ${ }^{10}$, as categorias de alimentos sob monitoração, em sua maioria, são os alimentos destinados a dietas ou a grupos populacionais específicos (indicados para controle de peso e os de transição para lactentes e crianças de primeira infância). Estas categorias foram selecionadas, primeiramente, em virtude de infrações observadas, como a alegação de propriedades terapêuticas em alimentos, delegando a este alimento uma suposta inocuidade. Foi observado o uso frequente de expressões como: ausência de efeitos colaterais; sem contra-indicações, atribuindo ao alimento uma característica de medicamento.

O Manual preconiza algumas informações obrigatórias que devem constar de forma legível em todos os Alimentos para Fins Especiais, respeitando a categoria a qual pertencem, segundo a Portaria SVS/MS n 29, de 13/01/989. Grande parte das peças publicitárias avaliadas neste estudo não atendia às diretrizes legais quanto a este item e, quando isto ocorria, a legibilidade era baixa, tornando-as quase imperceptíveis.

\section{Marcas das estratégias de indução ao consumo}

A principal marca do emissor foi a indicação do site e o telefone (0800) para contato, estratégia usada para garantir a informação, caso fosse interesse do consumidor obtê-la, sendo ao mes- mo tempo uma forma de chamariz para o consumo: a presença do site e telefone conferem legitimidade ao fabricante em relação a sua responsabilidade com a qualidade do seu produto, na medida em que estas estratégias sugerem transparência e representam uma forma de dialogar com o consumidor. Portanto, aumentam a probabilidade de convencimento. Entretanto, informações relevantes, como a nutricional ou a composição do alimento, que também poderiam ser apresentadas, acabaram sendo secundarizadas.

Outra característica observada do emissor foi o estabelecimento da relação entre bons hábitos de vida com uma dieta equilibrada vinculada ao consumo do produto em questão. Em algumas das peças verificou-se o patrocínio de esportes associado ao produto, como recurso para aumentar a confiança dos consumidores.

Como marcas do destinatário, identificamos que as peças falavam a um leitor interessado na boa forma com saúde, sendo que a maioria dirigia-se ao público feminino e veiculava informações sobre alimentos com restrição de nutrientes, que apresentam um profundo apelo para aqueles que buscam incessantemente um corpo perfeito. De fato, hoje, este valor tem estado em alta entre as mulheres, na procura de atender aos padrões estéticos impostos pela sociedade moderna. Neste sentido, Douglas e Isheerwood argumentam que o papel do consumo a partir do século XX tem sido influenciar a construção de novas referências públicas, ou seja, do lugar social que se deseja ocupar, do estilo de vida que se busca partilhar e, principalmente, representa uma forma de projeção individual ${ }^{18}$.

No caso dos alimentos infantis, o foco também foi a mulher, pois a escolha do melhor representa o cuidado com os filhos: não basta apenas amar, é preciso escolher o melhor, o melhor alimento, a melhor marca, o mais completo, o mais gostoso, etc. A escolha pelo alimento significa o aprofundamento dos laços de carinho da mãe com o filho e a certeza do que há de melhor no mercado para oferecê-lo. No estudo de Brites ${ }^{19}$ sobre a infância, a higiene e a saúde na propaganda, a autora relata que nos anos 50 a propaganda das indústrias alimentícias descrevia seus produtos como ricos em vitaminas e adequados para colaborar com a infância saudável e feliz. A publicidade em jornais e revistas anunciava uma série de produtos destinados à formação do corpo forte, sendo que naquela época a robustez infantil era sinônimo de saúde.

Hoje, esta robustez não vem sendo destacada nas propagandas de alimentos, mas a caracterís- 
tica de criança feliz e inteligente ainda é sinônimo de boa alimentação (desde que consumam o produto em questão). Outro forte apelo foi observado na relação do alimento com a certeza de um futuro promissor.

As principais marcas da linguagem foram: forte recurso à adjetivação, a intertextos culturais e a metáforas; uso de termos em outro idioma, como marca de sofisticação e expressões de efeito sem base técnico-cientifica. De acordo com Alves, o sucesso mercadológico da publicidade depende de associar um universo de determinados signos que, ligados metaforicamente ao produto, sejam capazes de o identificar a um conjunto de práticas e valores pertinentes a um determinado grupo de consumidores em potencial. E, ainda, a comunicação publicitária é produzida mediante a elaboração de narrativas que interfiram nos modos de apreensão do mundo, funcionando como orientadores, sugerindo condutas ${ }^{20}$.

$\mathrm{Na}$ maioria das peças publicitárias analisadas, a linguagem imagética foi predominante, privilegiando o resultado obtido pós-consumo e a satisfação obtida. A parte textual operava como um complemento, com frases curtas, ricas em adjetivos soando com grande efeito. Em algumas das peças, a linguagem foi marcadamente metafórica, buscando efeitos de associação entre o consumo do produto e um estado de espírito ou a uma situação almejada. Expressões como: $a$ vida pode ser doce; todo mundo adora; para quem quer mais da vida; saúde pra dar e beber; mais energia, leveza e bem-estar para o seu dia; toda mãe quer o melhor para o seu filho; enriquecido com bom humor e alto astral são algumas das expressões observadas. Em uma das peças, o selo de uma entidade conferia legitimidade ao produto, com indicativo de segurança e em outra, palavras em inglês como forma de caracterizar sofisticação ao produto. Constatou-se que expressões do tipo Exclusivo Actifibras; Prebio; Smothies, foram usadas para conferir legitimidade, embora estas não apresentem significado técnicocientífico, sendo apenas recurso retórico de persuasão do consumidor. Esta estratégia foi observada em algumas das propagandas de bebida à base de soja e duas bebidas lácteas.

De acordo com a legislação sanitária de alimentos, é vedada a veiculação de propagandas diferentes daquelas aprovadas para constar na sua rotulagem. Provavelmente, a difusão de informações deste tipo acarretará dúvidas ao consumidor, pois ele pode supor sobre a existência destas substâncias. Esta situação defronta com os preceitos estabelecidos pelo Código de Defesa do Consumidor, legitimado pela Lei $n^{\circ} 8.078$ de 11 de setembro de $1990^{21}$, que obriga o fornecedor a informar de forma clara o tipo e a composição do alimento, os riscos eventuais à sua ingestão, bem como a proteção contra a publicidade enganosa.

As principais marcas das mensagens (atributos do produto, principalmente) foram as imagens que expressavam felicidade, vitalidade, disposição, saúde física e mental; as características atribuídas ao produto: superioridade, credibilidade, confiança, alta qualidade, inovação e beneficio a saúde; personalidades da mídia conferindo legitimidade ao produto; o prazer, a satisfação e a saúde como álibis contra a culpa do consumo; convites para experimentar os outros produtos da linha ou marca; algumas peças induziam à substituição de refeições; atributos diet $\mathrm{e}$ light receberam destaque e em alguns casos empregados de forma inadequada; informações nutricionais e advertências em relação ao uso do produto eram inexistentes ou quando presentes apresentadas sem destaque.

A estratégia de indução ao consumo de alimentos pode ser comparável às estratégias desenvolvidas para estimular o consumo de medicamentos. O estudo desenvolvido por Nascimento $^{22}$, com 237 reportagens veiculadas em jornais e revistas nas décadas de 1980 e 1990 sobre alguns dos medicamentos mais consumidos no país, evidenciou que o consumo destes não estava relacionado apenas aos fins terapêuticos mas também a objetivos de moldar o corpo ou o comportamento em atendimento a padrões estéticos e de conduta estabelecidos na cultura. A autora descreve que a estratégia discursiva de favorecimento ao consumo foi associar informações científicas a símbolos de poder, beleza, juventude e força, tal como as propagandas de alimentos, que atribuem ao produto uma mistura de emoções e benesses físicas.

Como no estudo de Nascimento ${ }^{22}$, alguns dos alimentos também foram associados à imagem de artistas e atletas famosos, imprimindo ao alimento o status de milagroso. Em tais situações, exime o consumidor da culpa pelo consumo do produto, pois o alimento contribuiria para a boa forma física, além de ser saboroso. Em alguns casos, sugeria-se ao consumidor a substituição de refeições pelo produto, pois refeições hipercalóricas são impeditivas para aqueles que almejam tornarem-se parecidos às personalidades da mídia.

Comparando o presente estudo com os resultados daquele sobre medicamentos, observou- 
se que, em geral, são atribuídas aos produtos alimentícios propriedades relacionadas à saúde, à beleza e à tranquilidade, como se fossem pílulas milagrosas para os males físicos e também os da alma. Algumas frases como: ...um leite com fibras solúveis que ajudam ofuncionamento do intestino, ativam o bom humor e elevam o seu astral; o encontro perfeito de sabor com saúde: frutas vermethas, damasco ou ameixa, com apenas 70 calorias; $o$ que você perde em peso ganha em elogios; garantia de estar bem nutrido de um jeito gostoso e equilibrado ilustram que não é possível dissociar a situação almejada do produto. Em algumas das peças publicitárias, alimentos e medicamentos dividiam os mesmos holofotes e em alguns casos o alimento em questão fazia parte de um programa de redução de peso. Esta é uma estratégia arrisca$\mathrm{da}$, pois o consumidor pode identificar que, para a obtenção do êxito com o uso do produto, deve complementar um com o outro. Esta é uma estratégia proibida pela ANVISA, na medida em que são atribuídas ao uso do alimento propriedades terapêuticas e/ou medicinais, ou ainda que o uso do alimento seja complementar ao uso do medicamento, ou vice-versa.

Outra característica observada, no caso destas peças, foi a presença de diferentes vozes e seus discursos, principalmente a da indústria farmacêutica (farmácias e laboratórios farmacêuticos) e a de atrizes famosas, que conferiam legitimidade à publicidade.

\section{Produtos Diet e Light}

Em relação aos produtos alimentícios diet $\mathrm{e}$ light, o discurso publicitário influencia fortemente as escolhas do consumidor, fortalecendo a tendência de priorizar alimentos diet e light em detrimentos dos convencionais. Esta escolha não é realizada necessariamente de forma plenamente consciente, devido às estratégias de fomento ao consumo. O uso de palavras em outro idioma pode representar não só obstáculos na compreensão das informações vinculadas pela rotulagem ou nas peças publicitárias, mas também a sugestão de um produto de superior qualidade. Para Celeste ${ }^{23}$, não há justificativa ou razão, além da comercial, para a permissão do uso de palavras que provavelmente sejam desconhecidas pela maioria da população.

Oliveira e Assumpção ${ }^{24}$ comentam que o consumo dos produtos diet e light vem aumentando e alguns problemas de ordem conceitual acabam por gerar confusões entre os consumidores. Ainda existe a ideia distorcida, para muitas pessoas, de que o termo diet está associado a produtos indicados exclusivamente para dietas e regimes de diabéticos, por acreditarem que estes produtos contêm baixa caloria e são isentos de açúcar. O termo light tem sido associado, principalmente, a pessoas que desejam consumir alimentos com baixas calorias ou baixo teor de gordura. A partir da década de 90, esta categoria de produtos ganhou novos adeptos, constituídos por gente jovem saudável, com alto poder aquisitivo e preocupada com a aparência e o culto ao corpo.

De acordo com esse contexto, os alimentos light vêm servindo de mola propulsora para o consumo ao mesmo tempo em que ratifica sua relação com o modismo. Por outro lado, Matta et al. ${ }^{25}$ alertam que mesmo diante da preocupação com a saúde e também pela busca por um peso saudável, cresce o número de pessoas que fazem uso dos mais diversos tipos de dietas e de produtos diet e light, com ou sem orientação nutricional. Em contrapartida, de acordo com Ramos, existem vários erros na rotulagem dos alimentos comercializados no Brasil, sendo os atributos diet e light aqueles que mais contribuem para a publicidade enganosa em seus rótulos ${ }^{25}$.

A maioria das peças publicitárias avaliadas fazia menção a esta informação nutricional e em alguns casos equívocos foram constatados, ou seja, emprego do termo light ao invés de diet. Matta et al. afirmam que, de acordo com a Portaria $\mathrm{n}^{\circ} 27$, de 13 de janeiro de 1998, para ser atribuída ao alimento a denominação de light, este deve ter, no mínimo, 25\% menos de algum componente, seja ele calórico ou não ${ }^{25}$. A denominação de alimento diet fica reservada para aqueles que apresentam restrição a um dos ingredientes de sua formulação, não necessariamente o açúcar ou carboidrato, podendo também ser isento de gorduras, sódio, proteínas ${ }^{24}$. Este último é o alimento que é classificado como sendo Alimento para Fins Especiais.

Quanto às informações nutricionais, o destaque dado tem a finalidade de ressaltar a superioridade do produto e informar que este pode ser consumido sem restrições. Esta informação, nas peças avaliadas, é de caráter pontual, ou seja, $0 \%$ de açúcar, ou $0 \%$ de colesterol ou $0 \%$ de gordura. Estes componentes são estigmatizados como grandes vilões para aqueles que desejam a boa forma física. $\mathrm{Na}$ análise em pauta, as peças publicitárias que contemplavam alimentos infantis estavam de acordo com as determinações legais exigidas pela ANVISA, conforme a RDC n ${ }^{\circ} 222$, de 05 de agosto de $2002^{26}$, que aprova o Regulamento Técnico para a Promoção Comercial de 
Alimentos para Lactantes e Crianças de Primeira Infância, com o objetivo de regulamentar a promoção comercial e dar orientações sobre o uso apropriado dos alimentos para lactentes, visando promover, proteger e apoiar o aleitamento exclusivo, nos primeiros seis meses de vida e continuado até os dois anos ou mais de idade, após a introdução de novos alimentos.

Chaud e Marchioni ${ }^{27}$ descrevem que conceitos inadequados, incorretos ou polêmicos ainda são veiculados pela mídia com relação à alimentação de grupos vulneráveis como gestantes, lactantes e lactentes. O controle da propaganda, no caso dos alimentos infantis, talvez seja uma questão de mais urgência, pois visa evitar o incentivo ao desmame precoce, com a possibilidade da prevenção de afecções neste grupo populacional. Desta forma, é importante exigir o cumprimento das determinações legais pelas agências de publicidade e indústrias alimentícias, proibindo a divulgação de peças publicitárias ou instrumentos que induzam as mães a esta prática.

Nas peças analisadas, observou-se que as advertências sobre o uso adequado do produto, nem sempre receberam destaque em relação ao conjunto da peça. Outro dado que chamou atenção foi que, em uma das peças avaliadas, sobre uma bebida à base de soja, deu-se o destaque à propriedade do produto em conter apenas $0 \%$ de colesterol. Esta informação é de grande apelo publicitário e está em desacordo com as diretrizes permitidas pela legislação vigente $\left(\mathrm{RDC} \mathrm{n}^{\circ}\right.$ 259 , de 20 de setembro de 2002) ${ }^{28}$, pois como se trata de uma bebida de origem vegetal, de fato não pode conter colesterol, que é uma gordura tipicamente de origem animal. A ausência de informações e as informações enganosas são lesivas ao consumidor, na medida em que direcionam escolhas menos conscientes.

Chaud e Marchioni ${ }^{27}$ também constatam que conteúdos equivocados sobre alimentação, nutrição, suplementos alimentares e de emagrecimento são frequentemente disseminados pela mídia. A divulgação da informação está mais pautada em critérios publicitários do que propriamente informativos sobre as características nutricionais acerca do produto, não possibilitando os esclarecimentos importantes para os consumidores.

Deve-se ressaltar que, mesmo diante dos anúncios publicitários que cumprem as diretrizes legais, outras questões são evidenciadas. O consumidor se apropria das informações que são vinculadas nas peças publicitárias ou nos rótulos dos alimentos? Existe uma identificação com a sua realidade? O que elas dizem ao consumidor?
O que deve ser priorizado e sobreposto a qualquer interesse de mercado é o direito à informação, garantido a todo cidadão, possibilitando a capacidade de reflexão sobre as suas necessidades de consumo. Assim, o Estado, que deve garantir os interesses da sociedade, tem a obrigação de coibir práticas ilícitas ou enganosas que coloquem em risco a saúde dos indivíduos, além de garantir que seja respeitado o direito básico e inalienável a uma informação adequada, suficiente e correta sobre os produtos comercializados. Como afirma Burrowes ${ }^{5}$, assumir tal posição não configura um julgamento moral, a celebrar ou condenar o consumo como distração, ou como forma de satisfação de necessidades, mas aponta para a reflexão sobre todo o modelo implicado na satisfação desse consumo.

\section{Últimas palavras}

A legislação sanitária tem a finalidade de estabelecer critérios higiênicos-sanitários para que os alimentos disponíveis ao consumo apresentem qualidade e segurança e não coloquem em risco a saúde do consumidor. Assim, erros nas informações da rotulagem ou da propaganda do alimento comprometem toda a cadeia produtiva e aquele que deve ser protegido do risco acaba ficando ainda mais exposto. O compromisso com a saúde do consumidor deve ser primeiramente pactuado entre um Estado compromissado e uma indústria cumpridora dos preceitos legais.

Diante dos resultados obtidos e anteriormente discutidos, a análise das peças publicitárias mostrou que os recursos de sedução e indução ao consumo, próprias da publicidade moderna, levam a desconsiderar ou mesmo escamotear a necessidade de esclarecimento sobre os aspectos nutricionais dos alimentos. Alguns direitos são negados ao consumidor: o direito à informação, o direito à saúde, o direito a escolha consciente. Pode-se perguntar: a liberdade preconizada pela economia de mercado pode se sobrepor a esses direitos? Ou o direito à informação deve estar sobreposto às razões econômicas e de produção? E como estabelecer os limites nesse território fluido das significações? A monitoração é possível e eficaz como forma de controle? O Estado tem responsabilidade de propiciar informação à população sobre os alimentos. Porém, apenas informação leva a uma escolha consciente e crítica? São muitas as perguntas e ainda dispomos de poucas respostas. $\mathrm{O}$ tema pede mais estudos e investimento. 


\section{Colaboradores}

Marins BR foi responsável pela idealização da proposta, coleta e análise dos dados e elaboração do artigo. Araújo IS foi responsável pela revisão da abordagem teórico-metodológica, da discussão dos dados e revisão do texto e Jacob SC foi responsável pela revisão do artigo.

\section{Agradecimentos}

À Coordenação de Aperfeiçoamento de Pessoal de Nível Superior (CAPES) como órgão de fomento e a Pós-Graduação em Vigilância Sanitária INCQS/FIOCRUZ.

\section{Referências}

1. Araújo MFM, Rea MF, Pinheiro KA, Schmitz BA. Avanços na norma brasileira de comercialização de alimentos para idade infantil. Rev Saude Publica 2006; 40(3):513-20.

2. Pipitone MAP. Educação para o Consumo de Alimentos. Hig. aliment. 2005 19(132):18-23.

3. Santi PLR. Consumo e desejo na cultura do narcisismo. Comun. midia consumo 2005; 2(5):173-204.

4. Lyra RMS. Consumo, Comunicação e Cidadania. Ciberlegenda [periódico na Internet]. 2001; 6 [acessado 2007 nov] [cerca de 32p.]. Disponível em: http:// www.uff.br/mestcii/renata2.htm

5. Burrowes P. Viagem ao território da publicidade. Comun. midia consumo 2005; 2(5):205-19.

6. Araújo DC. O consumo e a mulher consumidora. Comun. midia consumo 2006; 3(7):147-65.

7. Nascimento A. "Ao persistirem os sintomas, o médico deverá ser consultado" Isto é regulação? São Paulo: Sobravime; 2005.

8. Brasil. Decreto-Lei n ${ }^{\circ} 986$ de 21 de outubro de 1969. Dispõe sobre as normas básicas sobre alimentos. Diário Oficial da União 1969; 21 out.

9. Brasil. Portaria SVS/MS no 29 de 13 de janeiro de 1998. Aprova o Regulamento Técnico referente a Alimentos para Fins Especiais. Diário Oficial da União 1998; 15 jan.

10. Agência Nacional de Vigilância Sanitária (ANVISA). Monitoramento de Propaganda de Produtos Sujeitos à Vigilância Sanitária. Brasília: Ministério da Saúde; 2005.

11. Brasil. Lei $n^{\circ} 11.265$ de 03 de janeiro de 2006. Regulamenta a comercialização de alimentos para lactentes e crianças de primeira infância e também a de produtos de puericultura correlatos. Diário Oficial da União 2006; 04 jan.

12. Henriques P, Ferreira DM, Dias PC. Regulamentação da propaganda de alimentos no Brasil: uma realidade em construção. Hig. aliment. 2006; 21(150):374-375.

13. Strozenberg I. O apelo da cor: percepções dos consumidores sobre as imagens da diferença racial na propaganda brasileira. Comun. midia consumo 2005; 2(4):199-220.

14. Araújo I. Mercado Simbólico: um modelo de comunicação para políticas públicas. Interface - Comunic., Saúde, Educ. 2004; 8(14):165-177.

15. Fortes PAC. Vigilância Sanitária, Ética e Construção da Cidadania. In: De Seta MH, Pepe VLE, Oliveira GOD, organizadoras. Gestão e Vigilância Sanitária: modos atuais do pensar e fazer. Rio de Janeiro: Fiocruz; 2006. p. 61-9.

16. Brasil. Lei no 8.080 de 19 de setembro de 1990. Dispõe sobre as condições para promoção, proteção e recuperação da saúde, a organização e o funcionamento dos serviços correspondentes e dá outras providências. Diário Oficial da União 1990, 19 set.

17. Costa EA, Rozenfeld S. Constituição da Vigilância Sanitária no Brasil. In: Rozenfeld S, organizadora. Fundamentos da Vigilância Sanitária. Rio de Janeiro: Fiocruz; 2000. p. 15-40. 
18. Enne ALS. À perplexidade, a complexidade: a relação entre consumo e identidade nas sociedades contemporâneas. Comun. midia consumo 2006; 3(7):11-29.

19. Brites O. Infância, higiene e saúde na propaganda (usos e abusos nos anos 30 a 50). Rev. bras. hist. 2000; 20(39):249-278.

20. Golobovante MC. Publicidade: o fazer-valer. Comun. midia consumo 2005; 2(3):139-53.

21. Brasil. Lei no 8.078 de 11 de setembro de 1990. Dispõe sobre a proteção do consumidor e dá outras providências. Diário Oficial da União 1990; 12 set.

22. Nascimento, MC. Medicamento, comunicação e cultura. Cien Saude Colet 2005; 10(Supl.):179-93.

23. Celeste RK. Análise comparativa da legislação sobre o rótulo alimentício do Brasil, Mercosul, Reino Unido e União Europeia. Rev Saude Publica 2001; 35(3):217-23.

24. Oliveira SP, Assumpção BV. Alimentos Dietéticos: evolução do conceito, da oferta e do consumo. Hig. aliment. 2000; 14(76):36-42.

25. Matta IEA, Henriques $\mathrm{P}$, Silva Y. Adequação à legislação vigente, da rotulagem de alimentos diet e light comercializados no Rio de Janeiro, RJ. Hig. aliment. 2006; 20(147):97-103.

26. Brasil. Resolução - RDC no 222 de 05 de agosto de 2002. Aprova o Regulamento Técnico para promoção comercial de alimentos para crianças de primeira infância. Diário Oficial da União 2002; 06 ago.

27. Chaud DMA, Marchioni DML. Nutrição e Mídia: uma combinação às vezes indigesta. Hig. aliment. 2004; 18(116/117):18-22.

28. Brasil. Resolução - RDC no 259 de 20 de setembro de 2002. Aprova o Regulamento Técnico sobre rotulagem de alimentos embalados. Diário Oficial da União 2002; 23 set.

Artigo apresentado em 07/05/2008

Aprovado em 05/02/2009

Versão final apresentada em 10/03/2009 